\title{
Correction to: A direct method to detect and localise damage using longitudinal data of ends-of-span rotations under live traffic loading
}

\author{
Alan J. Ferguson ${ }^{1}\left[\right.$ D $\cdot$ David Hester $^{2} \cdot$ Roger Woods $^{1}$
}

Published online: 12 January 2022

(c) The Author(s) 2022

\section{Correction to: Journal of Civil Structural Health Monitoring https://doi.org/10.1007/s13349-021-00533-5}

The update Fig. $2 b$ is given in this erratum, Thank original article has been corrected.

In the original version of the article, Fig. $2 b$ was printed incorrectly.

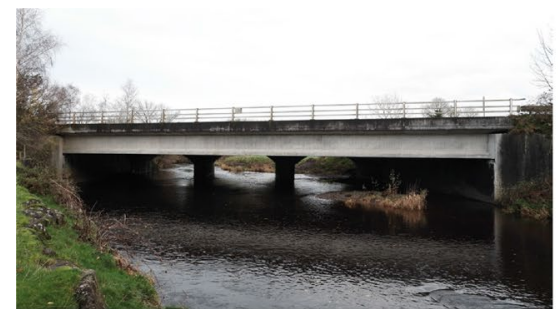

(a)

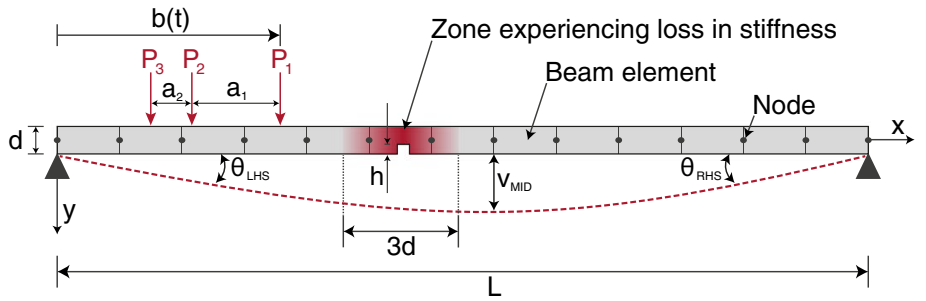

(b)

Fig. 2 a Photograph of West elevation of bridge; and $\mathbf{b}$ Sketch of the beam discretized model subject to a 3-axle vehicle (point loads $P_{1}$ to $P_{3}$ ) with measurements for midspan displacement and LHS and RHS rotations indicated

The original article can be found online at https://doi.org/10.1007/ s13349-021-00533-5.

Alan J. Ferguson

aferguson29@qub.ac.uk

David Hester

d.hester@qub.ac.uk

Roger Woods

r.woods@qub.ac.uk

1 School of Electronics, Electrical Engineering, and Computer Science, Queen's University Belfast, Belfast, Northern Ireland

2 School of Natural and Built Environment, Queen's University Belfast, Belfast, Northern Ireland

Publisher's Note Springer Nature remains neutral with regard to jurisdictional claims in published maps and institutional affiliations. 